\title{
Teenage Childbearing and Educational Attainment in South Africa
}

\section{Ian M. Timæus}

Professor of Demography, Department of Population Health, London School of Hygiene \& Tropical Medicine, Keppel Street, London, WC1E 7HT, United Kingdom. Email: ian.timaeus@1shtm.ac.uk; and Honorary Professor, Centre for Actuarial Research, University of Cape Town.

\section{Tom A. Moultrie}

Professor of Demography, Centre for Actuarial Research, University of Cape Town.

\begin{abstract}
Teenage childbearing and attainment at school in South Africa are investigated using nationallyrepresentative longitudinal data from the National Income Dynamics Study. The analysis focuses on the outcomes by 2010 of a panel of 673 young women who were childless and aged 15-18 in 2008. Controlling for other factors, girls who went on to have a baby had twice the odds of dropping out of school by 2010 and nearly five times the odds of failing to matriculate. Few girls from the highest-income quintile of households gave birth. Moreover, girls who attended schools in higher-income areas and were behind at school were much more likely to give birth than either girls in the appropriate grade for their age or girls at no-fee schools. New mothers were much more likely to have re-enrolled in school by 2010 if they were rural residents, belonged to relatively well-off households, or their own mother had attended secondary school. These findings suggest that, in South Africa, interventions that address poor attainment would also reduce teenage childbearing.
\end{abstract}

This article uses the National Income Dynamics Study (NIDS) to examine the role of teenage childbearing in young women's transitions to adulthood in South Africa. In particular, the paper focuses on the relationship between teenage childbearing and young women's subsequent schooling outcomes and the extent to which this relationship is accounted for by prior poor progress at school and economic disadvantage. It updates, validates, and extends the findings of previous research on this issue using nationally-representative, longitudinal data for 2008-10 that includes information on children's schools as well as their life histories and home backgrounds.

Teenage childbearing is less common in South Africa than most sub-Saharan African countries (Figure 1) and has gradually become less common in recent years (Moultrie and McGrath 2007; Branson et al. 2013). However, whereas in most of Africa the majority of teenage mothers are married, in South Africa they are not. This reflects the development of the country. Development both leads to, and is fuelled by, the expansion of mass secondary schooling. It requires young people to stay in formal education for a period that extends well beyond puberty. Thus, in South Africa, NIDS shows that by 2008 nearly all children aged 7-15 years were enrolled in school, and that no significant differences existed between boys and girls in enrolment (Timæus et al. 2013). Being in school, however, is inconsistent with marrying and fulfilling the adult roles associated with marriage (Furstenberg 1998). Equally, prolonged schooling and Westernization encourage the development of a distinct youth culture and social world in which premarital sexual activity can be legitimized. Together these trends tend to produce an increase in childbearing by girls who are still at school. At the same time, in South Africa, as elsewhere, teenage childbearing becomes increasingly seen as problematic, not only 
because it has become largely premarital, but also because of its potential consequences for girls' education and for both their and their children's future welfare (Jewkes et al. 2009; Panday et al. 2009). Thus, in South Africa, survey data suggest that more than two thirds of births to teenage mothers are unwanted (Panday et al. 2009).

\section{$<$ FIGURE 1 ABOUT HERE $>$}

Despite the progress that South Africa has made in improving children's access to and enrolment in school, the country still faces serious challenges with regard to the effectiveness of its schooling system. In particular, despite the high rate of participation in secondary education, only about 45 per cent of children successfully complete their final year of secondary school (Grade 12), by passing the senior certificate examination ("matriculate" in everyday parlance, although strictly only those students who pass with high enough marks to qualify them for admission to university should be described as matriculating) and this proportion rose hardly at all during the decade leading up to 2008 (Timæus et al. 2013). Their failure to pass the examination effectively rules out most forms of further and higher education and a wide range of skilled and white-collar jobs for more than half the young adult population.

Pregnancy is a important cause of dropping out of school for girls across sub-Saharan Africa (Eloundou-Enyegue 2004). In particular, according to the 1998 Demographic and Health Survey, pregnancy accounted for 36 per cent of girls who dropped out from secondary school in South Africa in the mid-1990s. In principle, the government of South Africa espouses progressive policies that encourage pregnant girls to remain in school and young mothers to return to school after giving birth. However, implementation of these principles varies between provinces and from school to school. Some schools ignore them and expel girls who become pregnant. More often, young mothers are debarred from returning to school in the year in which they give birth in line with a 2007 government policy that aimed to balance the interests of the mother and her infant (Republic of South Africa 2007). (This policy was ruled unconstitutional in July 2013, as it conflicts with the girls' right to an education). While other schools have more liberal policies on attendance, few of them have facilities for nursing and baby changing. Moreover, some teachers remain hostile to having pregnant girls and young mothers in school even when this contradicts their school's official position (Bhana et al. 2010; Morrell et al. 2012). Others, although not actively hostile, feel unable to offer girls additional support to assist them to return to school successfully. Thus, one far-reaching consequence of teenage childbearing is that it interrupts, and often terminates, girls' schooling.

Concern about teenage motherhood is also prevalent in high-income countries. The issue has been of particular concern in the United States and Britain, where teenage fertility is relatively high. Much of the literature emphasizes the adverse effects of teenage childbearing on the education and career prospects of the mothers (and sometimes fathers) and on the welfare of their children. However, while at one time the research evidence from the USA and elsewhere appeared to support Campbell's (1968) conclusion that "the girl who has an illegitimate child at the age of 16 suddenly has 90 percent of her life's script written for her", more recent research 
has tended to suggest that the poor outcomes of teenage mothers and their children result to a considerable degree from the confounding of teenage childbearing with pre-existing personal and familial disadvantages that are hard to measure and control for explicitly (e.g., Hoffman 1998). Thus, Furstenberg (1998) suggests that the conclusion that should now be drawn from the research literature is that "by the time a 16-year-old girl has a child, 70 percent of her life's script is already written for her".

Concerns about teenage motherhood in South Africa mirror those found in developed countries and also in other middle-income countries (Buvinic 1998). In addition to facing unsupportive or negative responses from many schools and educators, teenagers who become pregnant are stigmatized by most South Africans and are sometimes seen, not just as immoral, but as agents of social decay (Mkhwanazi 2012; Shefer et al. 2013). In particular, many of the media and public believe that young women are having babies in order to access welfare benefits, although the evidence cited in support of this view is no more credible in South Africa than anywhere else (Makiwane 2010).

In contrast to the negative views of teenage childbearing held by most South Africans, the research and policy oriented literature emphasizes that early motherhood is as much a consequence of social and economic disadvantage and gender inequalities as a cause of them (see, for example, the report produced for the Department of Basic Education by Panday et al. (2009)). It remains unclear, however, whether or not prior disadvantage accounts for as much of the association between teenage motherhood and subsequent adverse educational and other outcomes for girls in South Africa as in the developed world.

Research conducted in other contexts may not be generalizable to South Africa because the context in which teenage motherhood occurs in South Africa is distinctive in several ways. First, economic inequality in South Africa is more extreme than almost anywhere else in the world and the prevalence of absolute material deprivation remains high. Second, it has been argued that African societies in general, and those in South Africa in particular, tend to be more tolerant of premarital pregnancy than most Eurasian societies were until at least recently (Preston-Whyte and Zondi 1992; Jewkes et al. 2009). Third, one enduring consequence of the Apartheid system and the resulting system of labor migration between rural areas and places of employment has been the disruption of gender relationships and family life. Thus, an unusually high proportion of children do not live with their parents, and in particular with their father, and rather few teenage girls who become pregnant marry their children's fathers.

Fourth, another key component of the Apartheid system in South Africa was the segregated educational system. Separate schooling systems were established for each population group (i.e. African, Coloured, White and Asian, to use the terminology now favored in South Africa). Moreover, different systems existed in the core of the country and the so-called "homelands" and "independent states". Although education has been among the priorities of government since the collapse of the apartheid regime and accounts for about 20 per cent of public sector expenditure, the school system remains inadequate in many respects. A broad 
consensus exists among educationalists and education researchers in South Africa that, although the democratically-elected government rapidly established a color-blind schooling system and eliminated gross inequalities in the allocation of resources in the 1990s, the quality of many children's schooling in South Africa has remained low and progress toward securing more equitable outcomes has been limited (see, for example, van der Berg 2007).

Two previous studies in South Africa focus on the issues of central concern to this article. Grant and Hallman (2008) investigated the relationship between prior school performance and pregnancy-related dropout in a predominantly Zulu population in the Durban Metro and Mtunzini districts of KwaZulu-Natal. Their analysis is based on pregnancy and educational histories collected retrospectively from girls and young women aged 14 to 22 in 2001 . Both girls who enrolled late and girls who repeated a grade were more likely to have dropped out of school than other girls. Most strikingly, girls who had repeated a grade had 8.6 times the odds of other girls of experiencing a pregnancy-related school dropout and girls who experienced a pregnancy had almost double the odds of dropping out if they had repeated a grade. Young mothers were most likely to have re-enrolled if someone else was acting as the primary carer for their child and if there was an older working age woman in the household.

Marteleto et al. (2008) used longitudinal study data to investigate pregnancy and schooling in metropolitan Cape Town focusing on the outcomes during the next three years of a cohort of girls aged 14 to 16 in 2002. The girls' domestic circumstances, including their household's income per capita, whether they were living with their parents, and their parents' education, were unrelated to whether they became pregnant during the next 3 years. The fewer grades a girl had completed in 2002, however, the more likely she was to become pregnant. Girls who experienced a pregnancy, in turn, were more likely to drop out of school without matriculating than other girls. Having completed more grades in 2002 also directly reduced the probability that African, but not Coloured, girls would drop out.

While the evidence presented in these two papers suggests that the relationship between pregnancy and dropout in South Africa is confounded by prior progress at school, they have several limitations that we address using data from NIDS. Most obviously, each study only covered a small and atypical segment of South Africa's population. Second, while both studies examine dropout, neither explicitly investigated the determinants of success in the senior certificate examination, the endpoint of a school career of crucial importance for young people's futures. Thus Marteleto and her co-authors group "those who complete grade 12" and Grant and Hallman "young women who completed grade 12 successfully" with those who are still enrolled in school. In addition, because the study in KwaZulu-Natal was a single-round survey, its validity depends on the accuracy with which young women reported their pregnancy and educational histories retrospectively. Also, this study was unsuitable for assessing whether the relationship between progress at school and pregnancy is itself confounded by girls' prior socioeconomic circumstances and living arrangements as these characteristics were only measured at the endpoint of the histories reported by the young women. Both sets of 
characteristics are likely to have been altered by those histories. Lastly, but perhaps most importantly, neither analysis included any information on the characteristics of the schools that the girls attended.

Research on the determinants and consequences of teenage childbearing has been held back by a shortage of suitable longitudinal datasets not just in South Africa but in other less developed countries. Longitudinal data are essential if one is to distinguish young women's circumstances before giving birth from their current circumstances, which will have changed as a result of them becoming mothers. NIDS has collected nationally-representative data that can be used to untangle to what extent girls' progress at school in South Africa is held back by their family circumstances and household poverty, and to what extent by teenage pregnancy and childbearing, and how these factors relate to each other and to the inadequacies of the schooling system. In addition, it allows one to study the attainment of a cohort of children who experienced their entire schooling in the post-apartheid era.

Thus this article has four main objectives. First, it updates previous analyses to determine whether relationships identified in data collected in the period surrounding 2001 from children who started school under Apartheid still apply in 2010 in a cohort that has been educated entirely in a better-funded and integrated educational system. Second, it uses nationallyrepresentative data to establish whether relationships identified using data from KwaZulu-Natal and Cape Town apply to South Africa as a whole. Third, it conducts a longitudinal analysis to determine whether relationships established in cross-sectional studies of the country as a whole and of KZN arose because girls' circumstances determine whether they become teenage mothers or because becoming mothers alters their circumstances. Fourth, it takes advantage of the information on school characteristics that have been linked into NIDS to investigate whether such characteristics affect how likely pupils are to become teenage mothers and whether such effects confound some of the relationships observed in studies that lack these data.

\section{DATA AND METHODS}

NIDS is the first nationally-representative panel study to be mounted in South Africa. It received funding from the South African Presidency in order to monitor and investigate poverty in the country and is run by the Southern African Labour and Development Research Unit at the University of Cape Town. The baseline wave of NIDS in 2008 collected data on more than 28,000 people living in 7305 different households (Leibbrandt et al. 2009; Southern Africa Labour and Development Research Unit 2012a). A second wave of data collection took place in 2010 (Southern Africa Labour and Development Research Unit 2012b) and further waves of the study were conducted in 2012 and 2014. Only the data from the first two waves of the study have been analyzed here.

The study collects basic demographic data on all members of the panel and on other members of their households; information on their dwellings and access to utilities; information on the consumer durables owned by the households; and itemized income and expenditure data. 
Thus, it collects more detailed information on households' socioeconomic status than most demographic inquiries. It also asks about social grants, demographic events in the households, panel members' health, and other topics. Young people aged 15 or more are interviewed in person using the "adult" questionnaire. This form collects a birth history from female respondents and detailed data on the enrolment in school, progress and outcomes of respondents aged less than 30. NIDS also identifies children's schools and links several schoollevel indicators compiled by the national Education Management Information System (EMIS) to the individual-level survey data. Thus, it is a new and important resource for the study of inequalities in child welfare and the determinants of educational attainment in South Africa.

Longitudinal studies such as NIDS allow one to distinguish young mothers' circumstances before giving birth from their subsequent circumstances. The analyses presented here focused on the cohort of young women aged 15-18 in 2008 who at the time had not matriculated, were enrolled in school and had not yet had a baby. Most children in South Africa today now remain enrolled in school until at least the legal school-leaving age of 16 years (Anderson et al. 2001; Motala et al. 2007; Republic of South Africa 2013). Thus, although the final cohort of 673 young women only represents 78 per cent of the female population aged 15-18, it includes 92 per cent of the 15- and 16-year old girls.

Attrition of the sample is an issue in any panel study. The 2010 wave of NIDS successfully interviewed 77 per cent of the surviving young women identified as cohort members in 2008. In addition, a proxy respondent completed a shorter questionnaire on an additional 7 per cent of them, but these members of the panel were not included in the analysis because several key items of information are unavailable for them.

We investigated two educational outcomes. The first is whether the girls in our cohort who had not matriculated by the time of their interview in 2010 had dropped out of school and the second whether the subset of 273 girls who were in Grades 11 and 12 in 2008 had matriculated successfully from school. Thus, young women's educational outcomes are deemed unsatisfactory either if they left school without matriculating or if they remained in school in 2010 when they should have matriculated if they had made satisfactory progress. This may have happened either because they were held back from taking the senior certificate examination or because they failed it and returned to school to repeat Grade 12.

We also investigated what factors are associated with whether the young women gave birth during the two years of follow up, whether giving birth was associated with the young women's attainment at school and other characteristics, and what characteristics were associated with the re-enrolment in school by 2010 of the 111 young women in the cohort who had a baby between the two waves of fieldwork. We focus on teenage childbearing instead of teenage pregnancy both out of necessity, as NIDS does not ask about pregnancies that do not end in a live birth, and out of conviction as, although it is teenage pregnancy that often the subject of moral outrage, teenage motherhood usually has greater and more enduring consequences for young women's lives. 
The fertility-related outcome measure is based on all births to members of the cohort occurring between the 2008 and 2010 waves of NIDS. The fertility-related variable used as a predictor of attainment, however, only classified the birth as temporally prior to their educational outcomes for girls who remained in school in 2010 or who had already given birth or were at least 4 months pregnant when they left school. It does not include births that occurred after the girl had already dropped out or taken the senior certificate examination. We include pregnant girls in the explanatory variable because not only having a baby but also a visible pregnancy can make it more difficult for girls to sit or pass the senior certificate examination and may dissuade their parents or other carers from paying their school fees for the coming academic year or result in schools trying to discourage them from enrolling. Of course, our use of a 4-month cut-off to distinguish pregnancies that matter from those that do not is somewhat arbitrary. For example, some girls who took the senior certificate examination in their first trimester may have failed it as a result, while other girls may have been permitted to take the examination while heavily pregnant without this affecting their performance. Such misclassification biases will tend to attenuate our estimates of the impact that pregnancy and childbirth have on attainment.

As the senior certificate examinations take place in November, the analysis of whether giving birth or pregnancy reduces girls' odds of matriculating classified girls as having been potentially affected by all births occurring before the following May. The route by which approximately nine out of ten children dropped out was that they failed to enroll in school at the start of the academic year in January. For the analysis of the determinants of drop out, such girls were classified as having been potentially affected by births that occurred before June of the same year. NIDS does not collect information on the exact dates of drop out of the much smaller number of children who withdraw during the year. The cohort of 673 young women included 10 such dropouts who also had a baby during the year in which they dropped out. We classified the pregnancy as temporally prior to the dropout for the 8 of these girls who, when asked about this, stated that the reason why they had dropped out was because they were pregnant.

Although NIDS asked interviewees why they did not enroll in school, we only use this information for the 10 girls just mentioned as many of the young women who had a baby and then dropped out stated that they left school because they could not afford to continue their schooling. This may be true but, as Grant and Hallman (2008, p. 371) state succinctly: "for young women who mention such dominant concerns as financial issues, family obligations, or a lack of interest in school, a pregnancy may serve as an unacknowledged catalyzing force for the timing of school dropout".

The information collected from each household about the construction of their dwelling, its water supply and toilet was combined by means of a principal components analysis (PCA) into a single index of housing quality (Timæus et al. 2013). This index does not discriminate among the 30 per cent of the young women in the cohort who live in modern, well-constructed, fully-serviced dwellings. Similarly, PCA was used to construct a single consumer durables score 
for each household based on the ownership of nine different assets (Timæus et al. 2013). This index does not discriminate among the 18 per cent of the young women living in households that own none of these assets.

No information was obtained by NIDS on the highest educational attainment of the mothers of 5 per cent of the young women. As earlier research has suggested that this characteristic is an important determinant of aspects of educational attainment in South Africa and is highly confounded with socioeconomic status, these missing values were imputed by predicting the odds that the mother was in each educational category using an ordered logistic regression model that included the variables used in the subsequent analysis, race, and province of residence in 2008 (Timæus et al. 2013). Similarly, we estimated the likelihood that 9 per cent of fathers and 4 per cent of mothers were dead, rather than living apart from their daughters, using information on their survival in 2010 and other characteristics of the household.

Our exploratory analyses used several of the EMIS variables that have been linked to NIDS, including learner-teacher ratios and (as ex-White schools are widely perceived in South Africa to be better than other schools) which of the racially-differentiated educational systems the school belonged to before the collapse of the Apartheid system. However, only the fees status of the schools was found to be significantly associated with the outcomes we considered once other factors are controlled for. Thus, only it was used in the final analyses. This variable identifies schools located in the poorest 40 per cent of census tracts. These schools were eligible in 2008-10 to receive supplementary funding from government instead of charging fees. Although a few schools opt out of the arrangement, schools' actual policies on fees are not a matter of public record. In the interests of concision, therefore, this article describes all schools eligible for supplementary funding as "no-fees schools". Most of them were African schools prior to the collapse of the apartheid educational system and they tend to receive less funding in total than schools that charge fees and, therefore, to have worse facilities. Perhaps most importantly, as a result of these factors, they find it difficult to recruit their share of betterqualified and more effective principals and teachers.

No information was available from either the 2008 or 2010 rounds of data collection on the fees status of the schools of 60 of the 673 young women in the cohort under study. For 32 of these girls, we inferred their school's fees status from the answer to a question about the household's expenditure on the girl's school fees. For the other 28, we estimated the odds that they were attending a no-fees school using a logistic regression model with province, residence and the household's housing score as predictors.

All the demographic and educational outcomes examined are binary variables and have been modeled using logistic regression. Both the descriptive statistics and the regression coefficients and their standard errors have been adjusted for the fact that the panel was selected in 2008 using a weighted, stratified, and clustered sample design. 


\section{RESULTS}

According to NIDS, 35 per cent of South African women aged 20-34 in 2010 had their first child before their 20th birthday (Table 1). Moreover, only 48 per cent of women aged 20-34 had matriculated from school successfully. However, while only 33 percent of women aged 20-34 who had their first birth as a teenager had matriculated, 57 per cent of the rest of the women in this age group had done so.

As can also be seen from Table 1, substantial differentials existed in 2010 between demographic and socioeconomic groups in South Africa in both the incidence of teenage childbearing and educational attainment. Young White and Asian women were much less likely to have given birth as a teenager, and much more likely to have matriculated, than African or Coloured women. Moreover, women living in the best-off fifth of households were much less likely to have had a baby as a teenager than those in the poorer 60 per cent of households and fewer than a third of women aged 20-34 in the poorest fifth of households had matriculated, compared to 81 per cent of women in the best-off fifth of households.

\section{$<$ TABLE 1 ABOUT HERE $>$}

Elaboration of Table 1 demonstrates that the incidence of teenage motherhood and proportion of women who matriculated varied by income within the African population (results not shown). It provides no clear evidence, however, that the outcomes of middle-class African women differed from those of minority ethnic women. The cohort aged 15 to 18 that the analysis focuses upon includes only a handful each of White and Asian girls. Therefore, no attempt is made to estimate the impact of population group on the outcomes of the cohort.

Table 2 provides information on how many of the cohort of childless girls aged 15 to 18 who were enrolled in school in 2008 had progressed as far as Grade 11 or 12, left school without matriculating, matriculated between 2008 and 2010, and gave birth. It also provides weighted statistics describing the characteristics in 2008 of each of these four sub-groups of young women and of the cohort as a whole. Half the young women were living in urban areas in 2008. The young women' median reported monthly household per capita income was R383, which is about three-quarters of the South African poverty line and, in terms of purchasing power, equates to about US $\$ 3$ a day. Slightly more than two thirds of the girls were living with their mother and fewer than 40 per cent of them with their father. Half of them were in a lower school grade than one would expect, given their year of birth, if they had enrolled in Grade 1 on time at age 6 and progressed through the school system without interruptions or repeating a grade.

\section{$<$ TABLE 2 ABOUT HERE $>$}

The young women who had a baby between 2008 and 2010 were older, on average, than the cohort as a whole. They came from households with a lower median income per head than the other girls and relatively few of them lived in households in the top income quintile. They were slightly less likely than other young women to be enrolled in a no-fees school in 2008 but three-quarters of them were behind at school. Young women who were not enrolled in school in 2010 despite not having matriculated were also highly likely to be behind at school in 2008 . They 
came from considerably poorer households than the other members of the cohort and were slightly more likely to live in rural areas. They were also much less likely to be living with their parents than other girls and fewer of their mothers had been to secondary school. In contrast, only a fifth of the young women in Grades 11 and 12 in 2008 who matriculated by 2010 were behind at school. They tended to come from relatively well-off households and were slightly less likely than all girls in these grades in 2008 to be attending no-fees schools. They were also more likely to be living with their parents. Two thirds of them were living in urban areas, compared to 60 per cent of all female students enrolled in Grades 11 and 12 in 2008.

Slightly less than a fifth of girls aged 15-18 who were enrolled and childless in 2008 gave birth by 2010. Experimentation with several specification of the income variable in the regression model presented in Table 3 shows the fertility of young women varied little with household income across the lower 80 per cent of the income distribution. However, as Table 1 suggested, young women from households in the top fifth of the income distribution (which in South Africa corresponds approximately to the middle class) were much less likely than other girls to have a baby by 2010. In other respects, the analysis provides only limited support for the hypothesis that whether these young women gave birth depended on their home circumstances: their odds of giving birth only varied moderately with the other socioeconomic measures, the indicators of their living arrangements and their mothers' level of schooling and none of the differences are statistically significant.

\section{$<$ TABLE 3 ABOUT HERE $>$}

One important factor linked to childbearing by young women is whether they were behind at school relative to their expected grade for their year of birth. Being behind at school only mattered, however, if the girls were attending a school that charged fees, not a no-fees school. The right-hand columns of Table 3 indicate that, controlling for age and other factors, the odds of giving birth of girls attending fee-charging schools who were behind at school were 4 times those of other girls at fee-charging schools $(p<0.01)$ and 2.4 times those of girls attending nofees schools. Adding these indicators of attainment at school and the fees status of schools to the regression model attenuates somewhat the relationship between urban residence and childbearing, reflecting the concentration of fee-charging schools in urban areas, but has little impact on the other regression coefficients This suggests that being behind at school is more than just a mechanism through which socioeconomic background was making itself felt: girls who were attending schools in "good" areas in 2008, but struggling academically, were more likely than other girls to have a baby during the following two years irrespective of their socioeconomic background and family circumstances.

By 2010, 15 per cent of the girls who were enrolled, childless and aged 15-18 in 2008 had left school without matriculating and 51 per cent of those of them who were enrolled in grades 11 and 12 had matriculated successfully. The rest of the girls were still enrolled, although nearly a quarter of this group were in Grade 11 or 12 in 2008 and so should have matriculated before 2010. As one would expect, having a baby was an obstacle to continuing at school: 25 per cent of 
young women who had a baby and were still enrolled in school four months into their pregnancy dropped out subsequently, whereas only 13 per cent of other girls dropped out. Moreover, only 20 per cent of girls enrolled in Grades 11 and 12 in 2008 who subsequently either reached the fourth month of a pregnancy ending in a live birth or had a baby before having matriculated managed to matriculate by 2010, compared to 59 per cent of their female classmates.

Table 4 shows that, after controlling for other factors, young women who gave birth between the two waves of NIDS while they were still enrolled in school had 2.1 times the odds of other young women of not being enrolled in 2010 and 4.8 times the odds of failing to matriculate from Grade 11 or 12. In addition, girls who were behind at school in 2008 had 2.1 times the odds of dropping out and 2.3 times the odds of failing to matriculate $(p=0.07)$ of other girls in the same grade. Their low matriculation rate is not because they already had a history of failing the examination. Because the cohort excludes young women aged 19 or more, hardly any of the girls were repeating Grade 12 in 2008.

\section{$<$ TABLE 4 ABOUT HERE $>$}

Leaving the measure of being behind at school out of the regression models increases the odds of dropout associated with giving birth slightly to 2.3 and the associated odds of failing to matriculate to 6.3; omitting the measure of whether the girls gave birth increases the odds of these two adverse schooling outcomes associated with being behind at school to 2.3 and 3.3 respectively (full results not shown). Thus, the association between having a baby and failing to matriculate results in part from confounding with being behind at school. Moreover, the link between being behind at school and matriculation is mediated in part by early childbearing. Being behind at school and giving birth, however, are close to being independently associated with girls' risk of dropping out of school.

Table 4 also shows that girls who did not live with their mother were more likely to drop out and either not to enter or to fail the senior certificate examination $(p=0.11)$ than other girls. Girls who did not live with their fathers also did less well at school. However, the full regression model indicates that this relationship is mediated by other factors. Girls from better-off households, as measured by ownership of consumer durables, were considerably more likely than other girls to remain enrolled in 2010 than other girls, but none of the measures of the girls' socioeconomic background were significantly related to their odds of matriculating successfully.

The finding that being behind the appropriate grade for their age in 2008 is strongly associated with both whether the girls had a baby during the next two years and their educational attainment raises the issue of what characteristics of girls were associated with them being behind at school in 2008. Table 5 reveals that both girls from lower-income households and those from relatively poor households, as measured by the consumer durables index, were much more likely than girls from relatively well-off backgrounds to be have been behind the grade for their age in 2008. It also reveals that, after adjusting for these characteristics of schools' intake, children were much more likely to be in too low a grade for their age if they were attending schools that charged fees than if they were attending no-fees schools. The implication is that, 
although children are more likely to be held back for a year in no-fees schools, once one has adjusted for the characteristics of their intake, schools that charge fees require a higher level of achievement before children are allowed to progress to the next grade.

\section{$<$ TABLE 5 ABOUT HERE $>$}

More than half (57 per cent) of the members of the cohort who gave birth for the first time between 2008 and 2010 and had yet to matriculate were enrolled in school in 2010. The regression model in Table 6 examines who they were, controlling for both their age and the year in which they gave birth. As only 111 of the cohort of young women had a baby by 2010 and did not matriculate, the estimated odds ratios have very wide confidence intervals. Despite this, the analysis shows that relative wealth, as measured by the durable-goods index, and urban residence have large offsetting effects on re-enrolment. Controlling for other factors, particularly residence, reveals that new mothers living in relatively wealthy households in 2008 were much more likely to have re-enrolled in school than poorer mothers. On the other hand, controlling for the relative wealth of their household, young mothers living in urban areas were much less likely to have re-enrolled in school than those living in rural areas. While neither residing with their own mother nor having a relatively well-educated mother did much to protect teenage girls from early childbearing, new mothers whose own mothers had completed at least Grade 7 at school were highly likely to be enrolled in 2010. Thus, having a well-educated mother helped young women who had babies to get back into school promptly, perhaps because such mothers were more motivated than less-educated women to provide daycare for their grandchildren so that their daughters could complete their schooling. Lastly, it should be noted that, although girls who were in the correct grade for their year of birth in 2008 were more likely to have matriculated by 2010 and less likely to have had a baby than other girls, they were no more likely to have returned to school if they did have a baby than other young women.

\section{DISCUSSION}

Becoming a mother plays an important role in the failure of many young women in South Africa to matriculate. In many respects the findings of this study replicate those of earlier research: most of the results of research on geographically-localized studies apply nationally; findings arrived at using data collected around the turn of the century largely apply also to 2008-10; estimates based on cross-sectional data are only misleading in limited respects; and findings about the impact of children's characteristics and backgrounds are only biased to a small degree by failure to control for the characteristics of the schools that they attend. Nevertheless, exceptions exist to each of these generalizations. These new findings are highlighted in the course of this concluding section to the article.

First, this analysis of national data for 2008-2010 both supports and extends the findings of earlier studies conducted in Cape Town and KwaZulu-Natal that found that selection of girls who are behind the appropriate grade for their age into teenage motherhood explains some of this association. In other words, while some girls who would have otherwise have matriculated 
are prevented from doing so by the consequences of pregnancy and motherhood, girls who become mothers tend to be behind at school already and girls who are behind at school are relatively unlikely to matriculate even if they avoid early motherhood. Although NIDS did not collect the data on attitudes to schooling needed to establish this, it seems likely that other girls who are struggling to keep up at school or have become de-motivated will also be more likely to become pregnant while still at school. Girls who are doing well at school and have high hopes of passing the senior certificate examination, on the other hand, are probably highly motivated to avoid having a baby.

Teenage girls who are behind the appropriate grade for their age tend to be poor but in other respects comprise a diverse group. Some enrolled in school late, a smaller number will have failed to enroll in one or more subsequent years for health, financial or other reasons, and many of them will have been required to repeat one or more grades. Unfortunately, only twothirds of the cohort analyzed here reported their age at first enrolment, but modeling the data on this sub-group suggests that both late enrolment and having repeated grades raise girls' odds of giving birth as a teenager (results not shown). This accords with the study in KwaZulu-Natal, which distinguished the two factors and found that they independently affected the risk of teenage pregnancy (Grant and Hallman 2008).

Marteleto et al. (2008) found that, in Cape Town, the fewer grades girls had completed at school by ages 14 to 16 , the more likely they were to become pregnant subsequently. NIDS has linked data on schools to the survey data, allowing us to reach the more nuanced finding that girls who were behind at school only responded by becoming more likely to have a baby if they were attending schools that charge fees, not if they were attending a government-designated nofees school in a deprived area. As few no-fees schools are located in urban areas, this suggests that girls' behavior in such areas, including Cape Town, differs from that of girls in poorer, more remote rural areas, many of which are ex-"homelands". It is girls from low-income backgrounds attending fee-charging schools who are most likely to be behind at school and such girls that are at the highest risk of becoming mothers as a result of this.

One explanation of this finding might be that the school fees themselves matter. Girls from low-income backgrounds could be at risk of becoming sexually involved with men in the hope that their boyfriends will help them to pay their school fees. Alternatively, girls, or their parents, might be less likely to have a pregnancy terminated if this involves them in paying further school fees than if no fees have to be paid to keep the girl in school. More plausibly, those girls who find themselves failing educationally at a school that charges fees, who will often come from a relatively impoverished background, may experience a greater degree of stigmatization and alienation from the educational system than low achievers at no-fees schools. In addition, girls at schools that charge fees, which tend to be in urban areas, might be more likely to be sexually active than girls at no-fees schools but, when their attainment is satisfactory, also either more motivated or better able to avoid becoming mothers by means of contraception or obtaining terminations than girls who are either behind at school or attend a no-fees school. 
The socioeconomic background of teenage girls also shapes their transition to adulthood by other pathways. This analysis of NIDS suggests that girls from the highest-income fifth of households are much less likely to have a baby than other girls of the same age. This contrasts with Marteleto et al. (2008) finding that pregnancies are less common in high-income households among the Coloured population of the Cape Metro area, but not those among its African population. This might be because their analysis used a continuous measure of household income, because their sample includes few middle-class African girls, or because relative affluence affects behavior in Cape Town differently from elsewhere in the country.

Thus, poor educational attainment, teenage motherhood, and poverty in childhood and early adulthood are an interrelated cluster of social and economic problems in South Africa. Asset ownership and household income have been shown to be related to late enrolment and grade repetition at an earlier stage in children's schooling in other research based on NIDS (Timæus et al. 2013). They are shown here to protect against dropout during the second half of girls' teenage years. Moreover, girls who are behind at school, in turn, are not only more likely to have a baby than other girls, but less likely to pass the senior certificate examination when they do take it. The overall outcome of this web of influences linking socioeconomic status to examination success via progress at school and teenage childbearing is that, among all young women aged 17 to 18 in 2008, 52 per cent of girls from households in the top 60 per cent of the income distribution had matriculated by 2010, compared to only 29 per cent of girls from households in the bottom 40 per cent of the income distribution.

Having controlled for being behind at school and teenage childbearing, we found no evidence that the home backgrounds of teenage girls directly affect their chances of passing the senior certificate examination by 2010 . While one would like to believe that this implies that secondary schooling in South Africa is meritocratic, other research has suggested the more depressing conclusion that it is no more than a lottery (Lam et al. 2011).

The cohort of young women studied in this article is the first to have undergone its entire schooling in the national post-Apartheid educational system. Nevertheless, socioeconomic status and self-ascribed ethnic identity remain deeply intertwined in South Africa. Almost all White and Asian girls live in households in the top fifth of the income distribution. On the other hand, 53 per cent of girls from such households are African. Similarly, nearly all the no-fees schools attended by cohort members either used to be homeland or Department of Education and Training (i.e. African) schools or are schools established since 1994, but less than half the African girls attend no-fees schools. While race remains a huge economic, social and political issue in South Africa, this analysis of NIDS documents the crucial role that socioeconomic status now plays in shaping girls' transitions to adulthood in the country: the most important factor influencing the educational and fertility outcomes of a young, middle-class African woman is not that she is African, but that she is middle-class.

Girls who had babies were much less likely to have re-enrolled in school by 2010 if they lived in urban areas than rural areas. This is probably because it is more feasible for young 
women who have not matriculated to find paid work with which to provide for their baby in urban areas. Thus, the short-term benefits of the employment opportunities available to urban residents may be damaging in the longer run because they reduce young mothers' chances of completing their schooling (Madhavan and Thomas 2005). On the other hand, the fertility of young women may be similar in urban and rural areas because a higher incidence of conceptions in urban areas is offset by a higher incidence of both legal terminations of pregnancy and "backstreet abortions (Buchmann et al. 2002; Varga 2002). If this is the case, more academicallyinclined girls will be selected out of the group who proceed to have a birth to a greater extent in urban than rural areas.

Grant and Hallman's (2008) finding that co-residence with their mother does nothing to protect teenage girls from pregnancy is consistent with the evidence from NIDS. However, their results differ from those presented here in that they did not find that living with their mothers enabled more of the young women who had babies return to school. They found that teenage mothers were more likely to drop out if they were their child's primary caregiver, but that coresidence with the mother was unimportant even in a model that excluded this variable (Grant and Hallman 2006). They also failed to find any relationship between either urban residence or relative wealth and re-enrolment. This may be a feature of their study population. However, as the evidence from NIDS is that the latter two factors strongly offset each other, it might also reflect the fact that Grant and Hallman measured wealth ex-post facto.

This analysis of national data provided no evidence that living with their fathers protected teenage girls from pregnancy or improved their progress at school, although co-resident fathers were found to have a protective effect by two studies conducted at the beginning of the century in KwaZulu-Natal (Timæus and Boler 2007; Grant and Hallman 2008). Co-resident fathers may exert an influence on their teenage daughters' lives in KwaZulu-Natal that they do not elsewhere in South Africa. Alternatively, the two studies in KwaZulu-Natal may have picked up a transient association, whereby men who died during the early stages of the AIDS epidemic in South Africa came disproportionately from households with unmeasured characteristics that also led to poor outcomes for teenage girls.

South Africa resembles Western countries in that the association between teenage childbearing and poor educational outcomes is, in part, a selection effect. South Africa is distinctive, however, in that being in too low a grade for one's age plays a pivotal role in selecting girls into early motherhood. This is because it is common in South Africa for schools to require children to repeat a year if their learning is perceived to be inadequate. Doing so conveys a clear cut, if not necessarily accurate, message to a child that her progress at school is inadequate. This may be more de-motivating than the feedback indicating inadequate achievement that children receive in other educational systems. In addition, girls who are older than their classmates may become bored with and disengaged from school for this reason alone, rather than because they are pessimistic about their prospects of matriculating eventually. 
Ignorance about human reproductive biology and contraception remains rife among South African teenagers (Mchunu et al. 2012). Thus, one important intervention to reduce teenage pregnancy would be to improve further sex and life skills education (Magnani et al. 2005; Ahmed et al. 2009; Jewkes et al. 2009; Mathews et al. 2012). Provision of dedicated youth-friendly family planning services, including emergency contraception, and readier access to pregnancy termination services would also enable more teenage girls to avoid becoming mothers (Jewkes et al. 2009; Willan 2013).

Nevertheless, the career prospects of many teenage girls in South African are poor, especially if they live in remote areas, lack scholastic aptitude, or suffer from multiple disadvantages. Opting for motherhood is neither an irrational nor a completely negative course of action for some young women, but an alternative route by which to make the transition to adulthood. As Jewkes et al. (2009) put it, "teenage women infrequently make a decision to get pregnant, but much more commonly take few steps to prevent it. It is impossible to escape a conclusion that part of the reason for this is that they do not see it as such a bad thing for their lives and may perceive it to be desirable or advantageous".

By the time that they reach their mid-teens, therefore, it may be too late to motivate girls who have already given up on school to either abstain from sex or practice birth control effectively. Therefore, multipronged policy initiatives are required to address the "problem" of teenage pregnancy that not only enable young women to avoid unwanted pregnancies and births but also encourage young mothers to continue to invest in their own education and careers (Madhavan and Thomas 2005). By the same token, as Marteleto et al. (2008) argue, pursuing interventions that address the early roots of educational failure in South Africa would probably not only improve children's attainment but have the important knock-on benefit of reducing the incidence of teenage pregnancies.

The other side of the coin is that, notwithstanding the high rate of youth unemployment in South Africa, the economic and other benefits of completing school, matriculating, and perhaps proceeding to higher education, can be large. Like the young women from southern Cameroon described by Johnson-Hanks (2004), teenage mothers in South Africa who believe that they are capable of completing their schooling successfully have a strong incentive to postpone their second birth for an extended period in order to do so (Kaufman et al. 2001; Moultrie and Timæus 2003; Timæus and Moultrie 2008). Thus, the continuing high level of teenage fertility in South Africa and other more developed parts of sub-Saharan Africa may exert less of an upward influence on the overall level of fertility in such populations than the experience of other regions of the world might suggest.

We have found that girls from households in the top 20 per cent of the income distribution, which corresponds approximately to the middle class in South Africa, are much less likely to have a baby before they matriculate than other girls and are much more likely to return to school promptly if they do. In Western countries, teenage motherhood plays a role in the intergenerational transmission of disadvantage among those of low socioeconomic status. In 
South Africa, however, it is not the poorest, but middle-class, families that behave distinctively. The returns to education for today's teenagers may differ from those accrued by older generations. Until now, however, rather than teenage childbearing contributing to social disadvantage in South Africa, its relative rarity in middle-class families has played a role in the intergenerational transmission of privilege.

\section{ACKNOWLEDGEMENTS}

This work was supported by the United Kingdom's Economic and Social Research Council [grant number RES-238-25-0030] as part of the Pathfinder initiative for the collaborative analysis of micro data resources. 
TABLE 1 Differentials in early childbearing and completing secondary school (matriculating) in South Africa, 2010, women aged 20-34

\begin{tabular}{lcclcc}
\hline & $\begin{array}{c}\text { \% who gave } \\
\text { birth as } \\
\text { teenagers }\end{array}$ & $\begin{array}{c}\text { \% who have } \\
\text { matriculated }\end{array}$ & Sub-group & $\begin{array}{c}\text { \% who gave } \\
\text { birth as } \\
\text { teenagers }\end{array}$ & $\begin{array}{c}\text { \% who have } \\
\text { matriculated }\end{array}$ \\
\hline Sub-group & 35 & 49 & & & \\
\hline $\begin{array}{l}\text { Total } \\
\text { a) Age at first birth }\end{array}$ & & & c) Residence & & \\
$<20$ years & 100 & 33 & Urban & 31 & 53 \\
20+ years & 0 & 57 & Rural & 42 & 42 \\
b) Quintile of household income & & & & \\
Poorest & 43 & 30 & d) Population group & \\
$20-40 \%$ & 37 & 40 & African & 37 & 47 \\
$40-60 \%$ & 40 & 43 & Coloured & 37 & 41 \\
$60-80 \%$ & 34 & 56 & Asian & 2 & 73 \\
Best off & 16 & 81 & White & 10 & 74 \\
\hline
\end{tabular}

SOURCE: National Income Dynamics Study. 
TABLE 2 Numbers and characteristics of all young women aged 15-18 who were enrolled in school and childless in 2008, and of those of them who had given birth, left school without matriculating, and matriculated by 2010

\begin{tabular}{lccccc}
\hline & $\begin{array}{c}\text { All } \\
\text { women } \\
\text { in the } \\
\text { cohort }\end{array}$ & $\begin{array}{c}\text { Women } \\
\text { who } \\
\text { dropped } \\
\text { out }\end{array}$ & $\begin{array}{c}\text { Women } \\
\text { in Grades } \\
\text { 11 or 12 in } \\
\text { 2008 }\end{array}$ & $\begin{array}{c}\text { Women who } \\
\text { matriculated }\end{array}$ & $\begin{array}{c}\text { Women } \\
\text { who } \\
\text { gave } \\
\text { birth }\end{array}$ \\
\hline Characteristics in 2008 & 673 & 120 & 273 & 143 & 111 \\
Mean age & 16.4 & 16.7 & 16.9 & 16.7 & 16.9 \\
Mean grade & 9.2 & 9.0 & 10.4 & 10.5 & 8.9 \\
\% 1+ years behind the correct grade & 50 & 70 & 32 & 19 & 80 \\
for their age & 59 & 55 & 59 & 66 & 65 \\
\% enrolled in fee-charging school & 54 & 49 & 60 & 67 & 55 \\
\% living in urban areas & 386 & 322 & 444 & 484 & 322 \\
Median household income per head & & & & & \\
(rand) & 12 & 2 & 17 & 21 & 2 \\
\% in households with income per & -0.31 & -0.80 & -0.05 & 0.21 & -0.33 \\
head in the top quintile & -0.55 & -1.08 & -0.27 & -0.04 & -0.85 \\
Mean housing score & 68 & 51 & 64 & 73 & 60 \\
Mean consumer durable score & 61 & 50 & 68 & 69 & 57 \\
\% living with mother & 37 & 22 & 40 & 47 & 27 \\
\% with mother educated to Grade 7+ & & & & & \\
\% living with father & & & &
\end{tabular}


TABLE 3 Odds of giving birth between 2008 and 2010, girls aged 15-18 in 2008 who were enrolled and childless at that time, controlling for age in 2008

\begin{tabular}{lccc}
\hline Characteristics in 2008 & $\begin{array}{c}\text { Adjusted for } \\
\text { age in } \mathbf{2 0 0 8} \text { only }\end{array}$ & $\begin{array}{c}\text { Adjusted for age in } \\
\mathbf{2 0 0 8} \text { and other } \\
\text { background factors }\end{array}$ & $\begin{array}{c}\text { Fully } \\
\text { adjusted }\end{array}$ \\
\hline Urban compared with rural residence & 1.0 & 1.2 & 1.0 \\
Household income per head in top 20\% & $0.3^{* *}$ & $0.2^{*}$ & $0.2^{*}$ \\
Housing quality score & 1.0 & 1.0 & 1.0 \\
Consumer durables score & 0.8 & 0.8 & 0.9 \\
Mother resident in household & 1 & 1 & 1 \\
Mother not resident in household & 0.8 & 0.7 & 0.8 \\
Mother is dead & 1.3 & 1.0 & 1.0 \\
Mother's highest Grade 7+, compared to & 0.9 & 1.2 & 1.2 \\
Father resident in household & 1 & 1 & 0.8 \\
Father not resident in household & 0.9 & 0.8 & 1.2 \\
Father is dead & 1.5 & 1.2 & 1 \\
Enrolled in a no-fees school & 1 & & 0.6 \\
Correct grade for age; fee-charging school & 0.5 & & $2.4^{* *}$ \\
1+ grades behind; fee-charging school & $2.4^{* * *}$ & & \\
Number of young women & & 667 & \\
\hline
\end{tabular}

*Significant at $\mathrm{p} \leqslant 0.05 ;{ }^{* *} \mathrm{p} \leqslant 0.01 ;{ }^{* * *} \mathrm{p} \leqslant 0.001$.

SOURCE: National Income Dynamics Study. 
TABLE 4 Odds of dropping out of school and of failing to matriculate from Grades 11 and 12 by 2010, girls aged 15-18 in 2008 who were enrolled and childless at that time, controlling for grade in 2008

\begin{tabular}{|c|c|c|c|c|}
\hline \multirow[b]{2}{*}{$\begin{array}{l}\text { Characteristics in } 2008 \text { and fertility } \\
\text { history }\end{array}$} & \multicolumn{2}{|c|}{$\begin{array}{l}\text { Dropped out without } \\
\text { matriculating }\end{array}$} & \multicolumn{2}{|c|}{$\begin{array}{l}\text { Did not matriculate from } \\
\text { Grade } 11 \text { or } 12 \text { in } 2008\end{array}$} \\
\hline & $\begin{array}{c}\text { Adjusted } \\
\text { for grade } \\
\text { in } 2008\end{array}$ & $\begin{array}{c}\text { Fully } \\
\text { adjusted }\end{array}$ & $\begin{array}{c}\text { Adjusted } \\
\text { for grade } \\
\text { in } 2008\end{array}$ & $\begin{array}{c}\text { Fully } \\
\text { adjusted }\end{array}$ \\
\hline $\begin{array}{l}\text { Gave birth before or }<5 \text { months after } \\
\text { leaving school }\end{array}$ & $2.2^{*}$ & $2.1 *$ & $5.0^{* * *}$ & $4.8^{* *}$ \\
\hline $1+$ grades behind at school & $3.0 * *$ & $2.1 *$ & $3.5^{* *}$ & 2.3 \\
\hline Urban compared with rural residence & 0.8 & 1.9 & 0.7 & 1.2 \\
\hline $\ln$ (Household income per head) & $0.7 * *$ & 1.0 & 0.9 & 1.2 \\
\hline Housing quality score & $0.9 *$ & 0.9 & 0.9 & 0.9 \\
\hline Consumer durables score & $0.4^{* * *}$ & $0.4^{* *}$ & 0.8 & 0.9 \\
\hline Mother resident in household & 1 & 1 & 1 & 1 \\
\hline Mother not resident in household & $2.3^{*}$ & 1.9 & $2.6^{* *}$ & 1.8 \\
\hline Mother is dead & $2.3 *$ & 1.7 & 1.9 & 1.5 \\
\hline Mother's highest Grade $7+$, compared to $<7$ & $0.6^{*}$ & 0.7 & 1.2 & 1.4 \\
\hline Father resident in household & 1 & 1 & 1 & 1 \\
\hline Father not resident in household & $2.7 * *$ & 1.6 & $2.5^{*}$ & 1.3 \\
\hline Father is dead & $2.1^{*}$ & 0.9 & 1.6 & 1.1 \\
\hline Fee-charging compared with no-fee school & 0.8 & 1.3 & 0.5 & 0.5 \\
\hline Number of young women & \multicolumn{2}{|c|}{666} & \multicolumn{2}{|c|}{268} \\
\hline
\end{tabular}

*Significant at $\mathrm{p} \leqslant 0.05 ;{ }^{* *} \mathrm{p} \leqslant 0.01 ; * * \mathrm{p} \leqslant 0.001$.

SOURCE: National Income Dynamics Study. 
TABLE 5 Odds of being one or more grades behind the appropriate grade for one's age in 2008, girls aged 15-18 in 2008 who were enrolled and childless, controlling for age

\begin{tabular}{lcc}
\hline Characteristics in 2008 & $\begin{array}{c}\text { Adjusted for } \\
\text { age in 2008 }\end{array}$ & $\begin{array}{c}\text { Fully } \\
\text { adjusted }\end{array}$ \\
\hline Urban compared with rural residence & $0.6^{*}$ & 0.9 \\
ln(Household income per head) & $0.5^{* * *}$ & $0.7^{* *}$ \\
Housing quality score & $0.8^{* *}$ & 1.0 \\
Consumer durables score & $0.5^{* * *}$ & $0.6^{*}$ \\
Mother resident in household & 1 & 1 \\
Mother not resident in household & 1.0 & 0.9 \\
Mother is dead & 1.4 & 1.0 \\
Mother's highest Grade 7+, compared to $<7$ & $2.2^{* *}$ & 0.8 \\
Father resident in household & 1 & 1 \\
Father not resident in household & 1.4 & 1.1 \\
Father is dead & $1.9^{*}$ & 1.2 \\
Fee-charging compared with no-fee school & 1.0 & $2.5^{* *}$ \\
& \multicolumn{2}{c}{666} \\
Number of young women & \multicolumn{2}{c}{} \\
\hline
\end{tabular}

*Significant at $\mathrm{p} \leqslant 0.05 ;{ }^{* *} \mathrm{p} \leqslant 0.01 ; * * * \mathrm{p} \leqslant 0.001$.

SOURCE: National Income Dynamics Study. 
TABLE 6 Odds of new mothers enrolling in school in 2010, girls aged 15-18 in 2008 who were enrolled and childless at that time and did not matriculate by 2010 , controlling for age and the year when they gave birth

\begin{tabular}{lcc}
\hline Characteristics in 2008 & $\begin{array}{c}\text { Adjusted for age } \\
\text { and year in } \\
\text { which gave birth }\end{array}$ & $\begin{array}{c}\text { Fully } \\
\text { adjusted }\end{array}$ \\
\hline 1+ grades behind at school & 1.0 & 1.2 \\
Urban compared with rural residence & 0.4 & $0.1^{*}$ \\
ln(Household income per head) & 0.7 & 1.3 \\
Housing quality score & 0.9 & 0.9 \\
Consumer durables score & 1.5 & $2.8^{*}$ \\
Mother resident in household & 1 & 1 \\
Mother not resident in household & $0.2^{*}$ & 0.6 \\
Mother is dead & $0.2^{* *}$ & 0.3 \\
Mother's highest Grade 7+, compared to $<7$ & 2.2 & $6.2^{*}$ \\
Father resident in household & 1 & 1 \\
Father not resident in household & 0.4 & 1.3 \\
Father is dead & 1.3 & 0.4 \\
Fee-charging compared with no-fee school & 1.3 & \\
Number of young women & & 103 \\
\hline
\end{tabular}

*Significant at $\mathrm{p} \leqslant 0.05 ;{ }^{* *} \mathrm{p} \leqslant 0.01$.

SOURCE: National Income Dynamics Study. 
FIGURE 1 Percentage of women aged 20-24 who had a birth before age 18 by whether the birth occurred before first marriage, selected African countries

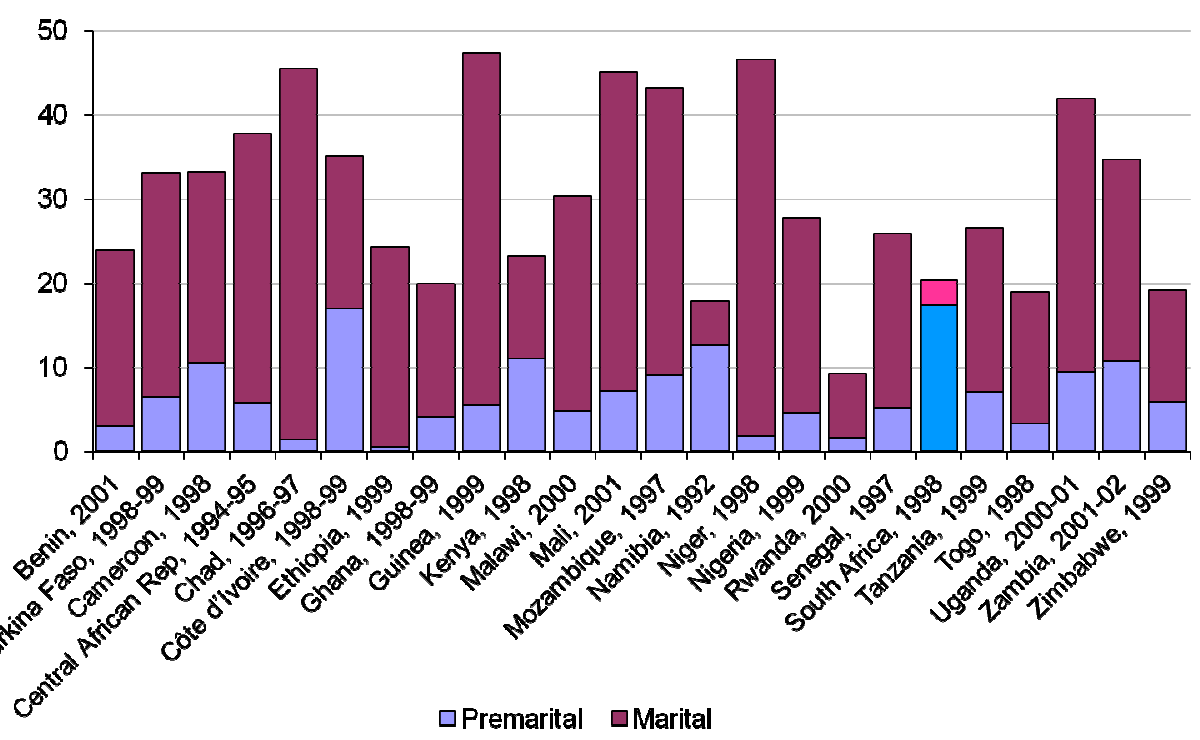

SOURCE: Authors' calculations from tabulations of Demographic and Health Survey data in Lloyd (2005). 


\section{REFERENCES}

Ahmed, Nazeema, Alan J. Flisher, Catherine Mathews, Wanjiru Mukoma, and Shahieda Jansen. 2009. "HIV education in South African schools: The dilemma and conflicts of educators," Scandinavian Journal of Public Health 37(2 suppl): 48-54.

Anderson, Kermyt G., Anne Case, and David Lam. 2001. "Causes and consequences of schooling outcomes in South Africa: Evidence from survey data," Social Dynamics 27(1): 37-59.

Bhana, Deevia, Robert Morrell, Tamara Shefer, and Sisa Ngabaza. 2010. "South African teachers' responses to teenage pregnancy and teenage mothers in schools," Culture, Health \& Sexuality 12(8): 871-883.

Branson, Nicola, Cally Ardington, and Murray Leibbrandt. 2013. "Trends in Teenage Childbearing and Schooling Outcomes for Children born to Teens in South Africa." SALDRU Working Paper 98. Cape Town: University of Cape Town.

Buchmann, E. J., K. Mensah, and P. Pillay. 2002. "Legal termination of pregnancy among teenagers and older women in Soweto, 1999-2001," South African Medical Journal 92(9): $729-731$.

Buvinic, Mayra. 1998. "The Costs of Adolescent Childbearing: Evidence from Chile, Barbados, Guatemala, and Mexico," Studies in Family Planning 29(2): 201-209.

Campbell, Arthur. 1968. "The role of family planning in the reduction of poverty," Journal of Marriage and the Family 30(2): 236-245.

Eloundou-Enyegue, Parfait M. 2004. "Pregnancy-related dropouts and gender inequality in education: A life-table approach and application to Cameroon," Demography 41(3): 509528.

Furstenberg, Frank F. 1998. "When will teenage childbearing become a problem? The implications of Western experience for developing countries," Studies in Family Planning 29(2): 246-253.

Grant, Monica, and Kelly Hallman. 2006. Pregnancy-related School Dropout and Prior School Performance in KwaZulu-Natal, South Africa. New York: The Population council.

Grant, Monica J., and Kelly K. Hallman. 2008. "Pregnancy-related school dropout and prior school performance in KwaZulu-Natal, South Africa," Studies in Family Planning 39(4): 369-382.

Hoffman, Saul. 1998. "Teenage childbearing is not so bad after all ... or is it? A review of the new literature," Family Planning Perspectives 30(5): 236-239, 243.

Jewkes, Rachel, Robert Morrell, and Nicola Christofides. 2009. "Empowering teenagers to prevent pregnancy: lessons from South Africa," Culture, Health \& Sexuality 11(7): 675-688.

Johnson-Hanks, Jennifer. 2004. "Uncertainty and the second space: Modern birth timing and the dilemma of education," European Journal of Population 20: 351-373.

Kaufman, Carol E., Thea Wet, and Jonathan Stadler. 2001. "Adolescent pregnancy and parenthood in South Africa," Studies in Family Planning 32(2): 147-160.

Lam, David, Cally Ardington, and Murray Leibbrandt. 2011. "Schooling as a lottery: racial differences in school advancement in urban South Africa," Journal of Development Economics 95(2): 121-136.

Leibbrandt, Murray, Ingrid Woolard, and Louise de Villiers. 2009. Methodology: Report on NIDS Wave 1. Cape Town: Southern Africa Labour and Development Research Unit.

Lloyd, Cynthia B. 2005. Growing up Global: The Changing Transitions to Adulthood in Developing Countries. Washington, D. C.: National Academies Press.

Madhavan, Sangeetha, and Kevin J. A. Thomas. 2005. "Childbearing and schooling: New evidence from South Africa," Comparative Education Review 49(4): 452-467.

Magnani, Robert, Kate MacIntyre, Ali Mehyrar Karim, et al. 2005. "The impact of life skills education on adolescent sexual risk behaviors in KwaZulu-Natal, South Africa," Journal of Adolescent Health 36(4): 289-304. 
Makiwane, Monde. 2010. "The Child Support Grant and teenage childbearing in South Africa," Development Southern Africa 27(2): 193-204.

Marteleto, Letícia, David Lam, and Vimal Ranchhod. 2008. "Sexual behavior, pregnancy, and schooling among young people in urban South Africa," Studies in Family Planning 39(4): 351-368.

Mathews, C., L. E. Aarø, A. Grimsrud, et al. 2012. "Effects of the SATZ teacher-led school HIV prevention programmes on adolescent sexual behaviour: cluster randomised controlled trials in three sub-Saharan African sites," International Health 4(2): 111-122.

Mchunu, G, K Peltzer, B Tutshana, and L Seutlwadi. 2012. "Adolescent pregnancy and associated factors in South African youth," African Health Sciences 12(4): 426-434.

Mkhwanazi, Nolwazi. 2012. "A tough love approach indeed: Demonising early childbearing in the Zuma era," Agenda 26(4): 73-84.

Morrell, Robert, Deevia Bhana, and Tamara Shefer. 2012. Books and Babies: Pregnancy and young parents in schools. Cape Town: HSRC Press.

Motala, Shireen, Veerle Dieltiens, Nazir Carrim, Paul Kgobe, George Moyo, and Symphorosa Rembe. 2007. Educational Access in South Africa. Brighton: Consortium for Research on Education, Access, Transitions and Equity.

Moultrie, Thomas A., and Ian M. Timæus. 2003. "The South African fertility decline: Evidence from two censuses and a Demographic and Health Survey," Population Studies 57(3): 265283.

Moultrie, Tom A., and Nuala McGrath. 2007. "Teenage fertility rates falling in South Africa," South African Medical Journal 97(6): 442-443.

Panday, S., M. Makiwane, C. Ranchod, and T. Letsoalo. 2009. Teenage Pregnancy in South Africa with a specific focus on school-going learners. Pretoria: Department of Basic Education.

Preston-Whyte, Eleanor, and Maria Zondi. 1992. "African teenage pregnancy: whose problem is it anyway?," in, Sandra Burman and Eleanor Preston-Whyte (eds.), Questionable Issue: Illegitimacy in South Africa. Cape Town: Oxford University Press, pp. 226-246.

Republic of South Africa. 2007. "Measures for the Prevention and Management of Learner Pregnancy." Pretoria: Department of Education.

- 2013. Education Statistics in South Africa, 2011. Pretoria: Department of Basic Education.

Shefer, Tamara, Deevia Bhana, and Robert Morrell. 2013. "Teenage pregnancy and parenting at school in contemporary South African contexts: Deconstructing school narratives and understanding policy implementation," Perspectives in Education 31(1): 1-10.

Southern Africa Labour and Development Research Unit. 2012a. "National Income Dynamics Study 2008, Wave 1 [dataset]. Version 4.1." Cape Town: DataFirst

. 2012b. "National Income Dynamics Study 2010-2011, Wave 2 [dataset]. Version 1." Cape Town: DataFirst

Timæus, Ian M, and Tania Boler. 2007. "Father figures: the progress at school of orphans in South Africa," AIDS 21(suppl 7): S83-S93.

Timæus, Ian M, and Tom A Moultrie. 2008. "On postponement and birth intervals," Population and Development Review 34(3): 483-510.

Timæus, Ian M., Sandile Simelane, and Thabo Letsoalo. 2013. "Poverty, race, and children's progress at school in South Africa," Journal of Development Studies 49(2): 270-284.

van der Berg, Servaas. 2007. "Apartheid's enduring legacy: Inequalities in education," Journal of African Economies 16(5): 849-880.

Varga, Christine A. 2002. "Pregnancy termination among South African adolescents," Studies in Family Planning 33(4): 283-298.

Willan, Samantha. 2013. "A Review of Teenage Pregnancy in South Africa - Experiences of Schooling, and Knowledge and Access to Sexual \& Reproductive Health Services." Durban: Health Systems Trust. 